\title{
Evaluation of Customer Preferences for Ready-to-Cook Dried Pork Product Attributes Using Conjoint Analysis
}

\author{
Pelapon Suwanacheep ${ }^{1}$ and Rungchat Chompu-inwai ${ }^{2+}$ \\ ${ }^{1}$ Master's Degree Program in Industrial Engineering, Faculty of Engineering, Chiang Mai University \\ ${ }^{2}$ Department of Industrial Engineering, Faculty of Engineering, Chiang Mai University, Thailand
}

\begin{abstract}
In developing ready-to-cook dried pork products which can provide satisfaction to consumers, it is necessary to know to which product attributes consumers give their preferences. This research has the objectives of analyzing product attributes of ready-to-cook dried pork products which affect consumer purchasing preferences with the techniques of Conjoint Analysis. The research methodology starts by seeking product attributes and their levels with Focus Groups. The attributes obtained were used to create a questionnaire and collect data from a sample group of 200 individuals. In their responses to the questionnaire, respondents were asked to rank a list of combinations of product attributes according to their satisfaction. This data was then analyzed for utilities values to find which product attributes contributed to consumer satisfaction and at what level. The results found that the most important attributes were flavorful taste, followed by standards of guaranteed tastiness, a price of $200 \mathrm{baht} / \mathrm{kg}$, type of pork meat used being either all lean or lean and fat and sodium levels in low-sodium products.
\end{abstract}

Keywords: Customer Preferences, Dried Pork Product, Conjoint Analysis

\section{Introduction}

The case study company is a factory producing and selling agricultural and food products, including fresh pork meat and products processed from pork meat which are sold and distributed in the North of Thailand. At latest, the company has developed a ready-to-cook dried pork product (Fig. 1). This has been put on sale to add value to the product and extend its storage life, by requiring consumers of the ready-tocook dried pork product to fry or bake it before consumption. However, the product has not been favored by consumers and suffered low sales. One problem may be that the company had not studied which attribute of the product had affected consumers' purchase decisions.

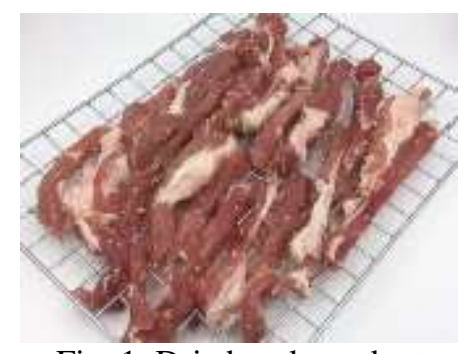

Fig. 1: Dried pork product

In the study of which attributes were given priority by consumers, if there is a list of individual product attributes for consumers to choose which attributes are important, consumers might reply that all attributes

\footnotetext{
+ Corresponding author. Tel.: + (66 53 944126); fax: +(66 53 944185)

E-mail address: rungchatc@hotmail.com
} 
are important. Besides this, consumers might look at one attribute on its own, rather than looking at many attributes together.

Conjoint Analysis (CA) is a technique used in Product Concept Development on the principle of considering many attributes jointly giving better results than consumers considering each attribute separately. Therefore, the $\mathrm{CA}$ technique gets consumers to rank a list of combinations of product attributes according to their satisfaction and then analyzing utilities values to find which attributes satisfy customers and at what levels these are appropriate.

Studies of the literature found that the CA method has been applied to the food industry on many occasions to analyze for attributes and the associated levels demanded by consumers of products and service [1]. For instance, [2] used the CA technique to analyze attributes of pork scratching products affecting the purchase preferences of consumers. The research results could be used to develop marketing strategies and give guidelines for product development.

The CA technique has two methods: Choice based Conjoint Analysis and Traditional Conjoint Analysis. [3] looked at the factors affecting target consumers of a corn snack product comparing both CA methods to find consumer demands, and found that both methods gave the same results, and either method could be chosen. However, [4] mentioned the limitations of the CA technique. For instance, researchers had to know which product attribute was affecting consumer satisfaction. As well as this, if there were too many attributes, it made collecting data from consumers difficult and complicated.

This research has the objective to study the attributes of ready-to-cook dried pork product affecting consumers' purchase preferences using the CA technique.

\section{Research Methodology and Results}

The researchers cited the CA methodology of [5] with the results of each stage as follows:

\subsection{Selection of attributes and attribute levels used in the research}

This stage was the selection of attributes and attribute levels used in the research. The attributes selected should cover every attribute used by consumers in purchase decisions and must be genuine attributes of the product. This research used the method of Focus Group Discussions with eight individuals in the Focus group aged 18-60, who were consumers of the dried pork product living in the urban district of Chiang Mai, Thailand. This was followed by analysis of data of consumer needs, done by grouping the data in an Affinity Diagram, which grouped similar needs and attributes to eliminate duplication and for ease of the analysis.

The case study company was then asked to select attributes and determine the levels of each attribute used in the research, which had to be attributes and levels which the company could realistically achieve. This was done by meetings between the researchers, production line managers and the head of the consultant team concerned with every aspect of business development and food solutions, who also had the position of head of marketing work and the head of sales, currently in charge of the ready-to-cook dried pork product sales. Table 1 summarizes attributes and attribute levels used in this research

Table 1: Attribute and attribute levels

\begin{tabular}{|l|l|}
\hline \multicolumn{1}{|c|}{ Attribute } & \multicolumn{1}{c|}{ Attribute level } \\
\hline 1. Taste & 1. Both sweet and salty, but more salty \\
& 2. Both sweet and salty, but more sweet \\
& 3. Both sweet and salty, and flavorful / rounded \\
\hline 2. Guarantees of tastiness & 1. Yes \\
& 2. No \\
\hline 3. Price & $1.200 \mathrm{baht} / \mathrm{kg}$ \\
& $2.220 \mathrm{baht} / \mathrm{kg}$ \\
& 3. $240 \mathrm{baht} / \mathrm{kg}$ \\
\hline 4. Sodium levels & 1. Normal \\
& 2. Low Sodium \\
\hline 5. Type of meat used & 1. All lean \\
& 2. Lean and fat \\
\hline
\end{tabular}




\subsection{Constructing concepts used in the research}

The total number of possible concepts can be found from taking the level of each attribute and multiplying them together. That is, from Table 1, taking the levels of all five attributes and multiplying them together to get $3 \times 2 \times 3 \times 2 \times 2=72$ concepts. However, according to [6], it is said that practically, if the number of concepts is too many to require the respondents to the questionnaire to evaluate, it will reduce the quality of the data. Therefore, the number of concepts must be reduced, with the method of Orthogonal Design or Fractional Factorial Design, which reduces the concepts to 16, as shown in Table 2.

Table 2: Concepts used in the research obtained from the Orthogonal Design technique

\begin{tabular}{|c|l|c|c|c|c|}
\hline $\begin{array}{c}\text { Con- } \\
\text { cept }\end{array}$ & \multicolumn{1}{|c|}{ Taste } & $\begin{array}{c}\text { Guarantee of } \\
\text { tastiness }\end{array}$ & Price & Sodium levels & Type of meat \\
\hline 1 & Both sweet and salty, and flavorful & No & 240 & Low Sodium & All lean \\
\hline 2 & Both sweet and salty, but more salty & Yes & 200 & Low Sodium & Lean and fat \\
\hline 3 & Both sweet and salty, and flavorful & Yes & 200 & Normal & Lean and fat \\
\hline 4 & Both sweet and salty, and flavorful & Yes & 220 & Low Sodium & All lean \\
\hline 5 & Both sweet and salty, but more salty & No & 220 & Normal & All lean \\
\hline 6 & Both sweet and salty, but more salty & No & 220 & Low Sodium & Lean and fat \\
\hline 7 & Both sweet and salty, and flavorful & No & 200 & Normal & Lean and fat \\
\hline 8 & Both sweet and salty, but more salty & Yes & 240 & Low Sodium & Lean and fat \\
\hline 9 & Both sweet and salty, but more sweet & No & 200 & Low Sodium & All lean \\
\hline 10 & Both sweet and salty, but more salty & No & 200 & Low Sodium & Lean and fat \\
\hline 11 & Both sweet and salty, but more sweet & Yes & 220 & Normal & Lean and fat \\
\hline 12 & Both sweet and salty, but more salty & Yes & 200 & Normal & All lean \\
\hline 13 & Both sweet and salty, but more salty & Yes & 240 & Normal & All lean \\
\hline 14 & Both sweet and salty, but more salty & No & 200 & Normal & All lean \\
\hline 15 & Both sweet and salty, but more sweet & No & 240 & Normal & Lean and fat \\
\hline 16 & Both sweet and salty, but more sweet & Yes & 200 & Low Sodium & All lean \\
\hline
\end{tabular}

\subsection{Design and collection / compilation of data}

This research determined a population group of the public aged 18-60 in the urban district of Chiang Mai, Thailand, which totalled 147,139 individuals as of 31 December, 2017 [7]. Research [8] stated that using CA in the study required data from 100-1,000 examples to be appropriate for the study. This research thus determined the number of examples in collecting data by using 200 example questionnaires and doing Accidental Sampling by requiring respondents to have previously been consumers of the dried pork product, to obtain data on attributes that could affect purchase decisions.

The questionnaire for the responding consumers was divided into three main parts:

Part 1: Questions about general information of the respondents - gender, age, income, educational level and general data as consumers.

Part 2: Questions about the behaviour of purchasing and consuming dried pork product and ready-tocook dried pork product.

Part 3: Questions about satisfaction of consumers with the 16 concepts of attributes (as detailed in paragraph 2.2). The method of presenting and showing the concepts for consumers to evaluate with the CA method can be done with many methods such as Pairwise Trade-Off Designs, Full Profile Design, Hybrid Conjoint Design and Adaptive Conjoint Analysis Design [9]. This research selected the Full Profile Design method by presenting all of the concepts simultaneously (by creating cards with images and descriptions of the attributes of each concept). Respondents were asked to rank the concept cards from the most satisfactory to the least.

\subsection{Selecting methods to measure satisfaction}

There are many methods to measure satisfaction such as giving Ratings, measured on a Cardinal Scale, while another popular method is giving rankings, which are measured on an Ordinal Scale. This research uses the latter method. Satisfaction is measured by getting consumers to rank concept cards and then applying Regression Analysis Using Least-Squares Method to approximate values of satisfaction with the product attributes. 


\subsection{Specification of preference model}

This stage of the methodology is the specification of a preference model. There are three popular models which are Discrete Model, Linear Model and Ideal-Point Model [10]. The Discrete Model is a method of estimating a utility model, which is suitable for attributes which are unpredictable in the direction of their changes after a change in attribute levels. The Linear Model shows relationships between satisfaction and attribute levels, which is appropriate for attributes which increase or decrease linearly with changes in attribute level. Finally, the Ideal-Point Model shows the relationships between satisfaction and attributes which is a curve and suitable for satisfaction increasing gradually to a maximum point with changes in attribute level, with further changes in attribute level leading to decreases in satisfaction. In the opposite way, the Anti-Ideal-Point Model is an inverted curve, with satisfaction tending to a minimum with changes in attribute levels, and subsequently increasing.

In this research, the Discrete Model was chosen for attributes of taste, guaranteed standards of tastiness, sodium levels and types of meat used, while the Linear Less model was chosen for the attribute of price, as values of satisfaction decrease with increasing price.

\subsection{Using the estimation method to estimate satisfaction of attribute levels}

Using the estimation method to estimate the satisfaction vales of each attribute level depends on the format of measuring satisfaction. If ratings are given to satisfaction, the methods used are MANANOVA and LINMAP. However, for ranking satisfaction, the methods used are logit, probit, hybrid, tobit and OLS. This study used the latter format of ranking satisfaction from high to low.

\subsection{Results}

Data collected from the 200 questionnaires was then analyzed. Goodness of fit of CA was analyzed and indicated by Kendall's Tau statistic. Kendall's Tau value was high $(=0.879)$ and p-value $<0.05(=0.00)$, indicating a strong and significant correlation between the actual and predicted preference ranking data [11]. It could be concluded that the model was satisfactory.

Next, the importance value of each product attribute and the utility estimate of each attribute level were analyzed as seen in Table 3.

Table 3: Importance value of each product attribute and utility estimate of each attribute level

\begin{tabular}{|c|c|c|c|c|c|c|}
\hline Attribute & Attribute Level & $\begin{array}{l}\text { Importance } \\
\text { Values }\end{array}$ & $\begin{array}{c}\text { Utility } \\
\text { Estimate }\end{array}$ & $\begin{array}{l}\text { Std. } \\
\text { Error }\end{array}$ & $\mathrm{t}$ & Sig \\
\hline \multirow{3}{*}{ Taste } & Both sweet and salty, but more salty $\left(\mathrm{X}_{11}\right)$ & \multirow[t]{3}{*}{35.848} & -0.612 & 0.259 & -4.765 & $0.000^{*}$ \\
\hline & Both sweet and salty, but more sweet $\left(\mathrm{X}_{12}\right)$ & & -1.097 & 0.332 & -9.759 & $0.000^{*}$ \\
\hline & Both sweet and salty, more flavorful $\left(\mathrm{X}_{13}\right)$ & & 1.710 & 0.277 & 14.777 & $0.000 *$ \\
\hline \multirow{2}{*}{$\begin{array}{l}\text { Standards } \\
\text { guaranteeing } \\
\text { tastiness }\end{array}$} & Yes $\left(\mathrm{X}_{21}\right)$ & \multirow[t]{2}{*}{18.382} & 0.743 & 0.189 & 8.412 & $0.000 *$ \\
\hline & No $\left(\mathrm{X}_{22}\right)$ & & -0.743 & 0.189 & -8.412 & $0.000^{*}$ \\
\hline \multirow{2}{*}{ Sodium levels } & Normal $\left(\mathrm{X}_{31}\right)$ & \multirow[t]{2}{*}{13.912} & -0.504 & 0.202 & -6.908 & $0.000^{*}$ \\
\hline & Low Sodium $\left(\mathrm{X}_{32}\right)$ & & 0.504 & 0.202 & 6.908 & $0.000 *$ \\
\hline \multirow{2}{*}{$\begin{array}{c}\text { Types of meat } \\
\text { used in } \\
\text { production }\end{array}$} & All lean $\left(\mathrm{X}_{41}\right)$ & \multirow[t]{2}{*}{15.197} & 0.136 & 0.194 & 1.505 & 0.134 \\
\hline & Lean and fat $\left(\mathrm{X}_{42}\right)$ & & -0.136 & 0.194 & -1.505 & 0.134 \\
\hline \multirow{3}{*}{ Price } & $200 \mathrm{baht} / \mathrm{kg}\left(\mathrm{X}_{51}\right)$ & \multirow[t]{3}{*}{16.661} & -5.379 & 2.640 & -5.602 & $0.000^{*}$ \\
\hline & $220 \mathrm{baht} / \mathrm{kg}\left(\mathrm{X}_{52}\right)$ & & -5.917 & 2.904 & -5.602 & $0.000 *$ \\
\hline & 240 baht $/ \mathrm{kg}\left(\mathrm{X}_{53}\right)$ & & -6.455 & 3.168 & -5.602 & $0.000^{*}$ \\
\hline & Constant & 100.00 & 12.096 & 2.812 & & \\
\hline
\end{tabular}

From the results of CA as shown in Table 3, it can be seen that the attribute of taste is the attribute given the most importance by the sample group in the purchase preferences for the dried pork product with an importance value of 35.848 , followed by the attribute of standards guaranteeing tastiness with an importance 
value of 18.382 , followed by the attribute of price, with an importance value of 16.661 , followed by the attribute of the type of pork meat used with an importance value of 15.197 and finally, the attribute of sodium levels with an importance value of 13.912 .

However, the attributes of the ready-to-cook dried pork product with a level of significance (or p-value) $<0.05$ numbered only four: taste, standards guaranteeing tastiness, sodium levels and price, which means that these 4 attributes are correlated with consumer satisfaction in a statistically significant way.

As for the attribute of the type of pork meat used in production, this did not have a statistically significant correlation with consumer satisfaction. That is, the type of meat used in production, whether all lean, or lean and fat, did not result in a significant change to the utility score. It was found that consumers satisfied with all lean, and those satisfied with lean and fat were in equal numbers.

From Table 3 it can be seen that utility estimates had different values at each attribute level. Looking at the overall picture, it is found that the utility estimate values for taste - "Both sweet and salty, but more flavorful" and "Certified Standards Guaranteeing Tastiness" had the two highest positive values in that order.

Subsequently, the utility estimate values were used to construct a linear regression equation to calculate utility scores or satisfaction with each product format $\left(\mathrm{U}_{\mathrm{k}}\right)$, as in $(1)$.

$$
\begin{gathered}
\mathrm{U}_{\mathrm{k}}=12.096-0.612 \mathrm{X}_{11}-1.097 \mathrm{X}_{12}+1.710 \mathrm{X}_{13}+0.743 \mathrm{X}_{21}-0.743 \mathrm{X}_{22}-0.504 \mathrm{X}_{31}+0.504 \mathrm{X}_{32} \\
+0.136 \mathrm{X}_{41}-0.136 \mathrm{X}_{42}-5.379 \mathrm{X}_{51}-5.917 \mathrm{X}_{52}-6.455 \mathrm{X}_{53}
\end{gathered}
$$

For taste attributes, it was found that the sample group were most satisfied with dried pork products that were "both sweet and salty, but more flavorful", followed by "both sweet and salty, but more salty" and "both sweet and salty, but more flavorful" in that order. From (1) it can be seen that if it is dried pork product with flavorful taste, the utility score is more greatly increased by 1.710 units. If it is dried pork product with salty taste, the utility score is reduced by 0.612 units. If it is dried pork product with sweet taste, this reduces the utility score by 1.097 units. This is consistent with the initial Focus Group Discussion. Most of the Focus Group stated that the attribute of taste had the most effect on consumer satisfaction.

For the attribute of standards guaranteeing tastiness, it was found that the sample group was more satisfied with ready-to-cook dried pork product which had been certified with standards guaranteeing tastiness than product which had not been certified with standards guaranteeing tastiness. From (1), it can be seen that if it was dried pork product which had been certified with standards guaranteeing tastiness, this increased the utility score by 0.743 units, but if it was dried pork product which had not been certified with standards guaranteeing tastiness, the utility score was reduced by 0.743 units.

As for the attribute of sodium levels, it was found that the sample group had more satisfaction with low sodium dried pork product, than product which had low sodium levels. From (1) it could be seen that if it was dried pork product with low sodium, this increased the utility score by 0.504 units, but if it was dried pork product with normal levels of sodium, this reduced the utility score by 0.504 units. This is consistent with the current reality that consumers have become more health-conscious by reducing the consumption of food with a salty taste, as excessive consumption of salt caused many diseases.

As for the attribute of the type of pork meat used in production, if it was all lean, the utility score increased by 0.136 units, but it was lean and fat, the utility score was reduced by 0.136 units. Although the sample group were more satisfied with dried pork product made with all lean, there was no statistically significant difference.

For the attribute of price, it was found that the sample group had the most satisfaction with dried pork product with a retail price of 200 baht per unit. If the dried pork product was priced at 200 baht per unit, this reduced the utility score by 5.379 units. However, if the dried pork product was priced at 220 baht per unit, this reduced the utility score by 5.917 units. If the price of the pork product was set to 240 baht per unit, this made the utility score reduce by 6.455 units. This was consistent with the reality that when product prices increase, consumer satisfaction tends to decrease.

It was also possible to calculate the satisfaction of consumers with each concept card, by calculating utility scores from (1). For instance, from Table 2, concept card no.1, i.e. the combination of both sweet and 
salty, with flavorful taste, no standard guaranteeing tastiness, a price of $240 \mathrm{baht} / \mathrm{kg}$, low sodium levels and using all lean pork, when replacing the values in (1), (2) is obtained with a utility score of 7.2480.

$$
\mathrm{U}_{\mathrm{k}}=12.096+1.710-0.743+0.504+0.136-6.455=7.2480 \text {. }
$$

It can also be seen that the concept cards where the product is both sweet and salty with a flavorful taste get a high utility score, such as concept cards 1,3,4 and 7, while concept cards with a product price of 240 baht $/ \mathrm{kg}$ tend to get low utility scores, i.e. concept cards $1,8,13$ and 15 .

\section{Conclusion and Discussion}

This research has the objective to study attributes of ready-to-cook dried pork products which affect the purchasing preferences of consumers using the CA technique. It was found that the attribute given most importance by consumers was being both sweet and salty with a flavorful taste, followed by having standards guaranteeing tastiness, a price of $200 \mathrm{baht} / \mathrm{kg}$, the type of pork meat used being either all lean or lean and fat, and low sodium levels in that order. The results of the research will be beneficial to the case study company to improve and develop its ready-to-cook dried pork products to cater to consumer satisfaction.

For future research, the number of examples in collecting data will be added. In addition, the researchers will use the Cluster Analysis technique in dividing groups of consumers according to satisfaction with attributes which are similar. The target groups will be determined by marketing, enabling the products to better reach the target group. The Cluster Analysis technique is a technique of separating data groups into sub-groups, with similar variables and data put in the same group.

Apart from this, the researchers will next use the Quality Function Deployment (QFD) technique for converting customer requirements into technical requirements appropriate for each stage of product development and the production process, enabling development of the product to match customers' needs.

Using the CA technique together with Cluster Analysis and the QFD techniques will help to reduce the risk of product development which is not accepted by consumers. It can enable the determination of appropriate marketing strategies as well as communicating the voice of customers in the design of production systems, resulting in reduced costs and fewer engineering design changes. Most importantly, they will increase customer satisfaction.

\section{Acknowledgements}

The authors gratefully acknowledge the financial support provided for the research by the Research and Researcher for Industry (RRI) fund 2017, a part of the Thailand Research Fund (TRF). The researchers would also like to thank the case study company and its staff for facilitating the research and giving their generous cooperation.

\section{References}

[1] J. Hauser, and V. Rao. Conjoint Analysis, Related Modeling, and Application. Advances in Marketing Research: Progress and Prospects. 2002, pp. 141-168.

[2] T. Thumrongpirun, A. Daloonpate, V. Limsombunchai. Attributes Affecting Consumers' Purchasing Decision on Pork Scratching. Department of Agricultural and Resource Economics. Faculty of Economics. Kasetsart University. 2559. (in Thai)

[3] K. Junnu, and K. Nantachai. Factors Affecting Target Consumer Acceptance for Ready to Eat Corn Products. Graduate Research Conference. Faculty of Technology. Khon Kaen University. 2557, pp. 476 - 482. (in Thai)

[4] T. Jaipan and C. Potchanasin. An Analysis of Optimal Tomato Juice Product Attributes for the Consumer in Bangkok Metropolis. Journal of Economics Ramkhamhaeng University. ISSN 2408-2643. Agribusiness. Faculty of Economics. Kasetsart University. 2559, pp. 53-76. (in Thai)

[5] A. Bajaj. Conjoint analysis: A Potential Methodology for IS Research Analysis. AMCIS, 1999. Available: https://aisel.aisnet.org/cgi/viewcontent.cgi?article=1595\&context=amcis1999, May 21, 2018.

[6] M. Piriyaku. Conjoint Analysis. Ramkhamhaeng University Journal. vol. 1, no. 2, 2012, pp. 252-272. (in Thai) 
[7] The Bureau of Registration Administration, Department of Provincial Administration. Population of Cities in Chiang Mai. 2561. Available: https://www.chiangmaihealth.go.th/cmpho_web/detail_article2.php?info_id=671

[8] D. Wittink, and P. Cattin. Commercial Use of Conjoint Analysis: A Survey. Journal of Marketing, 1982 , pp. 44-53.

[9] P. Green, A. Krieger, Y. Wind. Thirty Years of Conjoint Analysis: Reflections and Prospects. Interface, no. 31 (3, Part 2 of 2). 2001, pp. 56-73.

[10] J. Hair, R. Anderson, B. Tatham, W. Black. Multivariate Data Analysis, 6th Edition. New York: Prentice Hall. 2006, pp. 342-414.

[11] L. Shan, A. Brun, M. Henchion, C. Li, C. Murrin, P. Wall, F. Monahan. Consumer evaluations of processed meat products reformulated to be healthier - A conjoint analysis study. Meat Science 131, 2017, pp.82-89. 